\title{
Estimativa da degradação de fachadas com revestimento cerâmico: estudo de caso de edifícios de Brasília
}

\section{(Estimate of the facades degradation with ceramic cladding: study of Brasilia buildings)}

\author{
E. Bauer, E. K. Castro, M. N. B. Silva \\ Programa de Pós-Graduação em Estruturas e Construção Civil, Departamento de Engenharia Civil e \\ Ambiental, Faculdade de Tecnologia, Universidade de Brasília - UnB, \\ Campus Universitário Darcy Ribeiro, Brasília, DF \\ elbauerlem@gmail.com,kraus@unb.br,nazabsilva@gmail.com
}

\begin{abstract}
Resumo
No contexto da temática da avaliação de desempenho, vida útil, degradação e diagnóstico de patologias, tem-se observado que os edifícios construídos em Brasília vêm apresentando elevados casos de manifestações patológicas nas fachadas. Esses fenômenos vêm sendo observados em edifícios nas mais diferentes idades, induzindo a questionamentos importantes na parte técnica, relacionados à compatibilidade dos materiais constituintes do sistema de revestimento, técnicas construtivas, degradação dos materiais e projeto. Neste sentido, o objetivo deste estudo consiste em apresentar uma metodologia de inspeção, identificação e quantificação das manifestações patológicas que ocorrem com maior frequência nas fachadas dos edifícios. A metodologia proposta consiste em uma sistematização do processo de inspeção, com identificação, mapeamento e quantificação das manifestações patológicas em uma amostra de 90 fachadas. Essa metodologia permite estabelecer índices de intensidade de ocorrência de danos em função da orientação solar e da idade, bem como permite determinar a intensidade de manifestação patológica em diferentes regiões das fachadas (paredes contínuas, aberturas, sacadas, cantos e extremidades, juntas, transição entre pavimentos e topo). A amostragem é tomada no contexto dos edifícios de Brasília com idade na faixa de 5 a 48 anos. Os resultados mostram elevado fator de dano de descolamento cerâmico e evidenciam que os valores mais elevados dos fatores de danos foram observados nas fachadas Norte e Oeste e ainda nas fachadas com idade acima de 10 anos. Os resultados mostram também que os danos ocorrem com maior frequência na região das paredes contínuas. Este estudo visa contribuir com a necessidade de sistematização da identificação, classificação e quantificação dos danos em fachadas com revestimento cerâmico. Palavras-chave: revestimento cerâmico, manifestações patológicas, fator de danos, vida útil.
\end{abstract}

\begin{abstract}
In the context of the theme of the performance assessment, service life, degradation and diagnosis of pathologies has been observed that buildings constructed in Brasilia have high cases of pathological manifestations in the facades. These phenomena have been observed in buildings in many different ages, inducing relevant questions in the technical part, related to the compatibility of the materials and components, construction techniques, materials degradation and design. In this sense, the objective of this study is to present a methodology for inspection, identification and quantification of pathological events that occur most frequently on the facades of buildings. The proposed methodology consists of a systematization of the inspection process, identifying, mapping and quantification of pathologies in a sample of 90 facades. This methodology allows us to establish indices of intensity of damage in terms of solar orientation and age, as well as to determine the intensity of pathologies in different regions of the facades (continuous walls, windows, balconies, corners and edges, joints, transition between floors and top). The sample is taken in the context of buildings of Brasilia, Brazil, which ages range from 5 to 48 years. The results show the highest values of damage factors refer to ceramic detachment. It were observed, too, that the highest values of damage factors occur in the North and West facades in buildings with age over of 10 years. The results also show that damage occurs most frequently in the region of the continuous walls. This study aims to contribute to the need for systematic identification, classification and quantification of damage in ceramic facades.
\end{abstract}

Keywords: ceramic facades, pathological manifestations, damage factors, service life.

\section{INTRODUÇÃO}

A tipología básica das fachadas dos edifícios de Brasília emprega revestimentos com acabamento em argamassa e em placas cerâmicas, havendo muitos casos do uso misto dos dois sistemas. Os edifícios mais antigos de Brasília têm aproximadamente 53 anos e grande parte vem apresentando diversos tipos de manifestações patológicas nos sistemas de revestimento de fachadas. Os processos de degradação ocorrem, principalmente, em 
virtude da ação natural de envelhecimento ou ainda devido à exposição aos agentes atmosféricos [1]. Esse fenômeno de degradação também vem sendo observado em edifícios com menores idades, comprometendo a vida útil das fachadas.

Basicamente, a vida útil é "o período de tempo em que um edifício elou seus sistemas se prestam às atividades para as quais foram projetados e construídos considerando a periodicidade e a correta execução dos processos de manutenção" [2]. A vida útil das fachadas está diretamente relacionada à vida útil prevista em projeto, às características dos materiais, ao perfeito cumprimento das especificações de projeto executivo durante a construção como um todo, ao adequado uso e operação da edificação e de suas partes, à constância e efetividade das operações de limpeza e manutenção, além de alterações climáticas, níveis de poluição no local da edificação e mudanças no entorno da mesma ao longo do tempo [2-6].

A vida útil das fachadas sofre ainda a influência do comportamento das propriedades dos elementos (sistemas) e dos seus componentes (subsistemas) e da interação entre estes ao longo do tempo [7, 8]. Sendo assim, fachadas que apresentam manifestação patológica principalmente em idades precoces devem ser avaliadas no sentido de verificar quais foram os fenômenos de degradação que conduziram à perda de sua funcionalidade e, por conseguinte, provocaram um envelhecimento prematuro em função da vida útil prevista [9].

\section{Interação fachada-agentes de degradação}

As edificações estão sujeitas a movimentações diferenciadas causadas por tensões mecânicas, tensões térmicas, fadiga, choque térmico, expansão por umidade (elementos cerâmicos), infiltrações, esforços higrotérmicos, dentre outros fenômenos, podendo afetá-las de forma global ou em suas partes. A expansão por umidade dos elementos cerâmicos é um exemplo de fenômeno que ocorre em um elemento específico do sistema de revestimento, provocando danos diretamente no elemento cerâmico os quais podem levar ao descolamento, dentre outras anomalias $[10,11]$. Por outro lado, elevadas tensões térmicas e tensões mecânicas de tração podem provocar as falhas de aderência entre as diversas camadas do sistema de revestimento [12]. Neste sentido, qualquer fenômeno de degradação que ocorra em um ou mais de um elemento do sistema de revestimento poderá se propagar e, ao provocar um processo progressivo de degradação poderá comprometer o desempenho global da fachada [13].

Os sistemas de vedação e seus revestimentos, enquanto um subsistema da edificação e, por sua posição, se encontram frequentemente confinadas entre vigas e pilares. Esse estado de confinamento do sistema de revestimento, além do fato do mesmo ser composto por camadas com materiais cujas propriedades (módulo de elasticidade, coeficiente de dilatação térmica, condutividade térmica, calor específico, dentre outros) são bastante diferenciadas, provocam elevadas deformações e movimentações diferenciais capazes de se transformar em patologias $[14,15]$. Essa movimentação diferencial se propaga para cada elemento ou camada que compõe o sistema de revestimento (elementos cerâmicos, rejunte, argamassa colante e emboço) provocando o início do surgimento das primeiras degradações nas fachadas. Portanto, se o processo de degradação não for tratado no início, quando os danos são pequenos, poderá implicar em elevados custos de reparo no futuro, além da evolução da degradação leve para problemas físicos reais da fachada [1618].

Diversas pesquisas realizadas em Brasília relatam estudos de casos de manifestações patológicas de revestimentos de fachada $[19,20]$, entre outros. Esses estudos buscam identificar, entender e sistematizar os fenômenos que provocam as manifestações patológicas que surgem nas fachadas. Dentre esses estudos, ressalta-se o trabalho que, em pesquisa realizada para levantamento e a identificação de manifestações patológicas que ocorrem com maior frequência em sistemas de revestimentos cerâmicos de fachadas de edifícios na cidade de Brasília-DF, identificaram claramente uma diferença no percentual de danos entre os edifícios com idades até 10 anos e acima de 10 anos [20]. Estes pesquisadores evidenciaram o descolamento como o caso mais incidente (53\% para fachadas até 10 anos e $83 \%$ para fachadas acima de 10 anos) e também observaram um processo de transformação das patologias com o decorrer do tempo. Esse fenômeno é observado principalmente no caso da fissuração, que decresce nas idades mais avançadas enquanto ocorre acréscimo no percentual de descolamento de cerâmica e falha de vedação (Fig. 1). Esse estudo identifica as principais patologias encontradas, mostrando também as diferenciações entre os processos de degradação que caracterizam a distribuição de diferentes anomalias. Existe, todavia, a necessidade de estudos com enfoque mais detalhados que permita quantificar outras variáveis que influenciam os processos de degradação, tais como: as condições ambientais, a orientação cardeal (exposição), o nível de gravidade e a localização dos danos. Fica evidente, desta maneira, a necessidade de avanços ou sistematização das análises que envolvam a quantificação da degradação das fachadas.

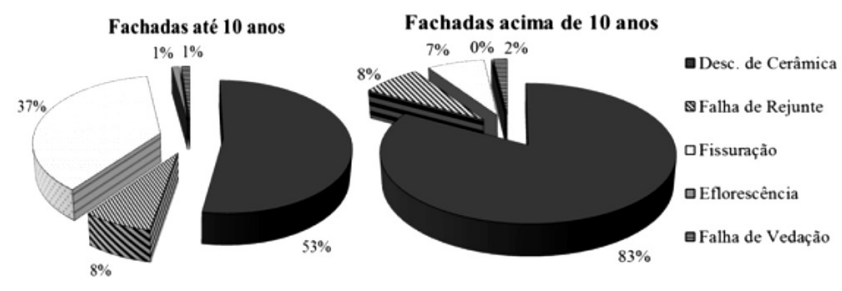

Figura 1: Percentual de manifestações patológicas em edifícios com idade até 10 anos e acima de 10 anos (adaptado [20]).

[Figure 1: Percentage of pathological manifestations in buildings aged up to 10 years and above 10 years (adapted [20]).]

A degradação da fachada pode ser atribuída aos efeitos combinados de diferentes mecanismos de degradação, 
ou seja, a sequência de alterações químicas ou físicas, ou ambas, que conduzam a alterações prejudiciais em uma ou mais propriedades dos componentes da fachada quando exposta a um ou mais fatores de degradação (incidência solar, chuva dirigida, dentre outros), tendo um forte impacto sobre o desempenho das edificações [21-24].

\section{Mapeamento das manifestações patológicas em revestimentos de fachadas}

A incidência de danos nas fachadas dos edifícios, representada pelo mapeamento das manifestações patológicas é apresentada e discutida quantitativamente na metodologia proposta por Gaspar e Brito (2005) [25] que definiram em seu estudo seis regiões de análise de fachadas. Em estudo posterior, Antunes (2010) [26] fez uma adaptação daquela forma de representação do mapeamento estabelecendo oito diferentes regiões de análise tipo nas fachadas (Fig. 2): (1) próximo ao nível do solo (caso haja contato com mesmo); (2) sobre paredes contínuas; (3) em torno das aberturas (janelas, portas, elementos vazados, etc.); (4) no topo (platibanda, abaixo de cornijas, rufos e beirais); (5) em sacadas ou varandas; (6) nos cantos e extremidades; (7) acerca (vizinhança) das juntas, e em havendo ausência de juntas de movimentação horizontal a cada pé direito; (8) na transição entre pavimentos. A metodologia de mapeamento adotada no presente trabalho se baseia no modelo de mapeamento definido por em 2010 [26].

O estudo de patologias de fachada consiste na análise de todos os casos observados nas fachadas e sua interação

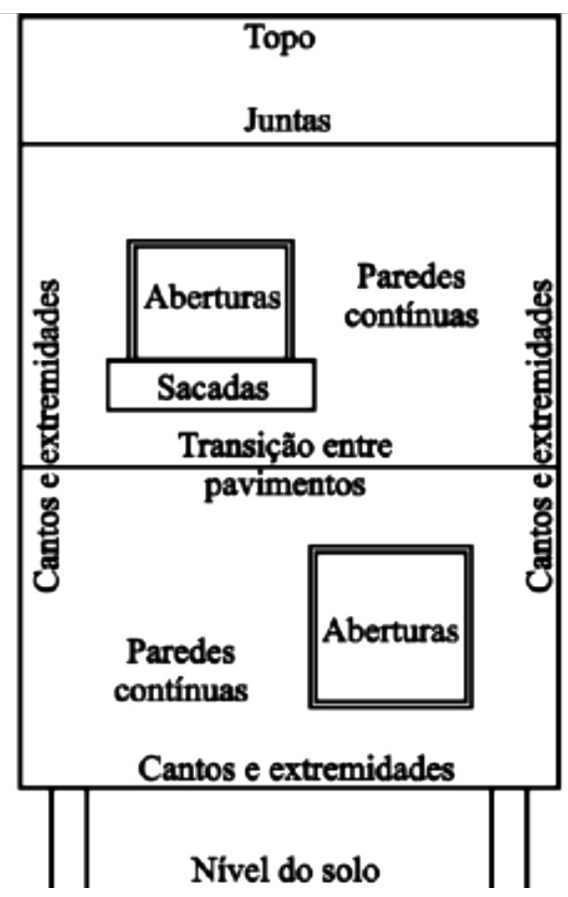

Figura 2: Representação esquemática das regiões de análise na fachada (adaptado [26]).

[Figure 2: Schematic representation of the regions of analysis in facade (adapted [26]).] com o meio ambiente, associando os fatores que causam as manifestações patológicas com os fenômenos de degradação observados na inspeção. Toda a abordagem, desde o levantamento de informações preliminares até o mapeamento necessita, obrigatoriamente, de grande sistematização. Neste sentido as manifestações patológicas são identificadas, posicionadas na região da fachada e quantificadas. A identificação de regiões que sejam mais suscetíveis aos processos de degradação é uma ferramenta importante para o entendimento dos mecanismos de deterioração que, por sua vez, poderá auxiliar em atividades de especificação e projeto de fachadas de edifícios mais eficientes e que futuramente apresentem desempenho adequado [25, 27].

Diante do exposto, este estudo consiste em identificar e medir a degradação das fachadas buscando classificar as diferentes anomalias e a frequência de ocorrência de danos por região. A degradação das fachadas é medida por um único valor quantitativo (fator de danos) obtido por meio do levantamento das quantidades de cada dano em função da área total da fachada.

\section{MÉTODOS}

\section{Levantamentos das degradações em fachadas}

Para efetuar os levantamentos dos danos detectáveis (descolamentos, falhas de rejunte, fissuração, eflorescência e falha de vedação) foram realizadas inspeções in loco efetuadas por uma equipe de especialistas do Laboratório de Ensaios de Materiais (LEM) da Universidade de Brasília. Essa equipe de especialistas desenvolveu uma metodologia de diagnóstico das principais manifestações patológicas nas fachadas dos edifícios em Brasília que integra as seguintes etapas: obtenção de informações preliminares, inspeção, ensaios e diagnóstico $[11,28]$. A metodologia do presente estudo se baseia na metodologia do LEM-UnB, porém se atém às duas primeiras etapas, a saber: obtenção de informações preliminares: que consiste na identificação histórica de intervenções, na disposição arquitetônica do edifício, na exposição a intempéries, na documentação das principais regiões deterioradas, com registro fotográfico amplo de todas as fachadas do edifício; inspeção compreende uma avaliação detalhada das regiões críticas ou de toda a fachada. Busca-se documentar a composição e detalhes construtivos (espessura) dos materiais de revestimento (argamassas, cerâmicas, alvenaria), bem como identificar as patologias. O resultado final é um mapeamento de patologias nas diferentes fachadas do edifício.

A identificação e obtenção dos danos nas fachadas foram feitas por intermédio de ferramentas auxiliares de inspeção (câmeras digitais/termográficas), para registro fotográfico e posterior mapeamento das manifestações patológicas visíveis, por prumada do edifício. Cada prumada representa uma amostra de fachada e é considerado, neste estudo, o espaço entre juntas estruturais verticais ou módulos da fachada. Os principais tipos de manifestações patológicas observadas durante os levantamentos são identificados como 
$[11,28]$ : descolamento ou desplacamento de cerâmica: ocorre quando a peça cerâmica perde a continuidade de contato com a argamassa, podendo ocorrer desprendimento parcial ou total da peça cerâmica ou ainda a ausência parcial ou total de aderência entre a peça cerâmica e a camada subjacente; falha de rejunte - o rejuntamento entre as peças cerâmicas fissurou e/ou se desprendeu, permitindo o acesso de água da chuva internamente; fissuração - observou-se fissura no revestimento; eflorescência - manchas brancas formadas pela deposição de sais oriundos da alvenaria ou do próprio revestimento; falha de vedação - danificação de juntas principalmente na circunvizinhança de janelas e aberturas, por onde ocorre penetração de água de chuva.

As Figs. 3 e 4 apresentam exemplos de amostras de fachadas dos edifícios analisados. As fachadas de edifícios de Brasília apresentam tipologias semelhantes, possuindo, em geral, 6 andares e pilotis com fachadas revestidas parcial ou totalmente com elementos cerâmicos. Vale ressaltar que, neste estudo, mesmo que existam amostras com composição de acabamento em elementos cerâmicos e outros diferentes tipos de acabamento, somente são considerados as regiões de fachada revestidas com elementos cerâmicos. As demais fachadas com acabamento em reboco, elemento vazado, pedras naturais, placas metálicas, dentre outros tipos não são consideradas neste estudo. A Tabela I apresenta as características das amostras das fachadas utilizadas neste estudo. Observa-se que foram inspecionados mais de $32.000 \mathrm{~m}^{2}$, sendo muito expressiva essa amostra de estudo.
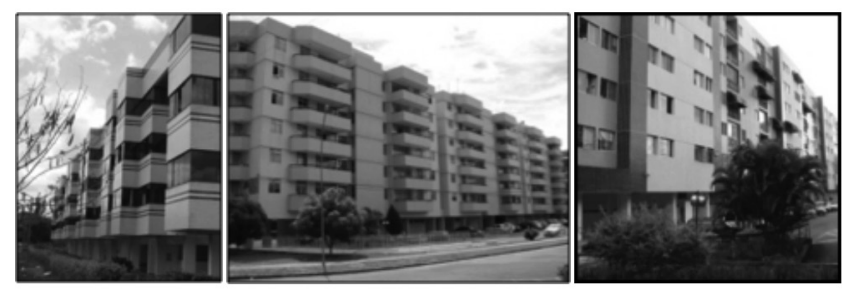

Figura 3: Fachadas de edifícios com idades até 10 anos.

[Figure 3: Buildings facades aged 10 years.]

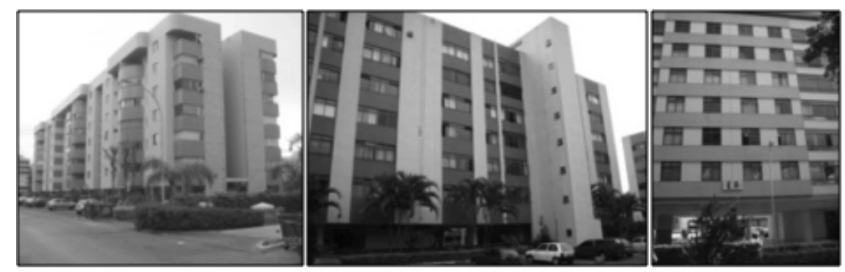

Figura 4: Fachadas de edifícios com idades acima de 10 anos.

[Figure 4: Buildings facades aged over 10 years.]

O mapeamento das manifestações patológicas (Fig. 5a) foi efetuado por intermédio de desenho representativo da fachada com detalhamento de todas as manifestações patológicas. Após o mapeamento, as fachadas dos edifícios foram divididas para proceder à contagem dos danos por região de análise e para determinar a incidência de dano por metro quadrado da fachada. Para tanto, são sobrepostas malhas com área de 0,25 $\mathrm{m}^{2}(0,50 \mathrm{~m} \times 0,50 \mathrm{~m})$ nas fachadas mapeadas (Fig. $\left.5 b\right)$ sendo cada malha a unidade básica de medida.
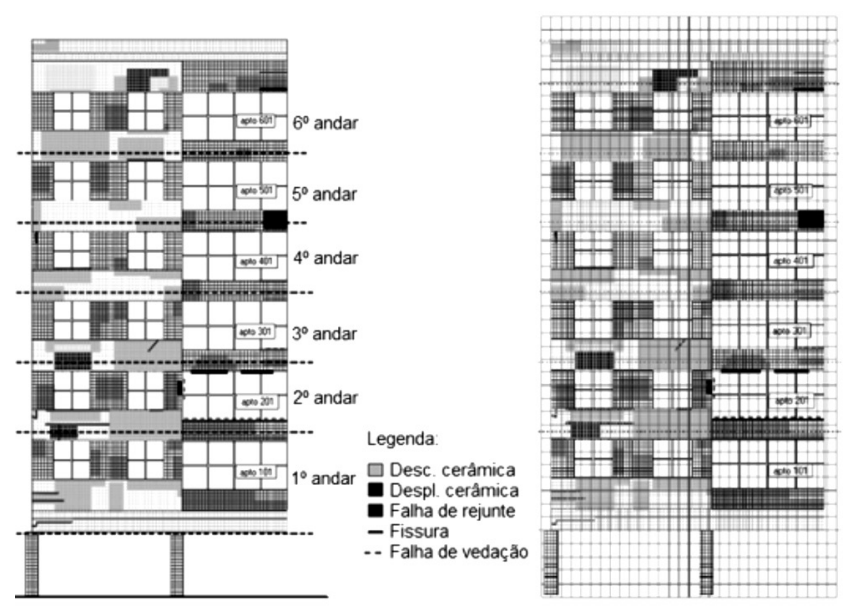

Figura 5: Esquema de mapeamento de danos e sobreposição da malha nas fachadas analisadas.

[Figure 5: Scheme damage mapping and overlaying the facade analyzed mesh.]

Quantificação das intensidades de ocorrência de danos em diferentes regiões das fachadas

O mapeamento de danos, efetuado através da sobreposição de malha, permite quantificar a frequência de ocorrência de manifestações patológicas de descolamento de cerâmicas, falha de rejunte, fissuras, eflorescência e falha de vedação em função de cada região específica da fachada: paredes contínuas, aberturas, sacadas, cantos e extremidades, juntas, transição entre pavimentos e no topo (Fig. 2). Os valores obtidos a partir dessa quantificação representam a porcentagem da área da fachada com incidência de manifestações patológicas.

\section{Índices e parâmetros de avaliação da degradação das} fachadas

O quantitativo das intensidades de ocorrências patológicas em metros quadrados auxilia a determinação de índices de avaliação dos danos. Em uma análise preliminar, cada tipo de dano $\mathrm{n}\left(\mathrm{n}_{1}=\right.$ descolamento de cerâmicas, $\mathrm{n}_{2}=$ falha de rejunte, $\mathrm{n}_{3}=$ fissuras, $\mathrm{n}_{4}=$ eflorescência e $\mathrm{n}_{5}=$ falha de vedação) é analisado em função da área total da referida amostra para determinar o fator de dano (FD) da fachada. Este fator de dano relaciona a área $\left(\mathrm{A}_{\mathrm{d}, \mathrm{n}}\right)$ de cada tipo de manifestação patológica em função da área total $\left(\mathrm{A}_{\mathrm{T}}\right)$ de fachada conforme mostra a equação A, permitindo, dessa maneira, mensurar o estágio preliminar puro de extensão da degradação das fachadas.

$$
\mathrm{FD}=\left(\mathrm{A}_{\mathrm{d}, \mathrm{n}} / \mathrm{A}_{\mathrm{T}}\right)
$$

Na qual FD é o fator de dano da fachada, $A_{d, n}$ a área de cada tipo de dano ou manifestação patológica observada na amostra de fachada $\left(\mathrm{m}^{2}\right)$, e $\mathrm{A}_{\mathrm{T}}$ a área total da amostra de fachada $\left(\mathrm{m}^{2}\right)$. $\mathrm{O}$ fator de dano da fachada permite estabelecer uma análise quantitativa inicial do estado de degradação de cada amostra de fachada através de uma distribuição bastante 
simples, cujas variáveis são somente a área de incidência de ocorrência do dano e a área total da amostra de fachada. Esse fator não considera, portanto, a interferência de mecanismos de degradação ou ponderação de variáveis (importância do tipo de dano ou custo de reparação). Entretanto, esta ferramenta é essencial, servindo como balizamento para análises mais complexas das manifestações patológicas em sistemas de revestimentos cerâmicos de fachadas.

\section{RESULTADOS E DISCUSSÃO}

Considerando que o objetivo deste estudo consiste na identificação, quantificação e localização das degradações das fachadas, são apresentados os resultados obtidos dos mapeamentos e análise da extensão da incidência de danos a partir de 90 fachadas inspecionadas em edifícios de Brasília. Os resultados são obtidos por intermédio da análise do levantamento, mapeamento, da intensidade de ocorrência das manifestações patológicas e do fator de danos (FD) das fachadas.

Os edifícios foram avaliados em função dos seguintes critérios: influência da orientação cardeal no fator de danos das fachadas; influência da idade no fator de danos das fachadas (duas faixas de idades: $\leq 10$ anos e $>10$ anos); influência das regiões das fachadas na média de distribuição de manifestações patológicas. Esses critérios de análise permitem estabelecer uma organização dos resultados do fator de danos, calculados a partir da equação A e ainda da distribuição da incidência de ocorrência de danos, obtidos a partir da porcentagem média para cada região de análise de danos das fachadas.

Influência da orientação cardeal no fator de danos das fachadas

A Tabela II mostra a média do fator de danos (FD) que ocorrem nas quatro orientações (Norte, Leste, Sul e Oeste). Cada coluna da Tabela II apresenta a média dos valores do fator de danos das amostras em função do tipo de dano ou manifestação patológica. $\mathrm{O}$ fator de dano quantifica a frequência de ocorrência das manifestações patológicas nas fachadas.
Tabela I - Características das fachadas de Brasília utilizadas na amostragem.

[Table I-Characteristics of the building facades in Brasilia.]

\begin{tabular}{lc}
\hline \multicolumn{2}{c}{ Amostra de estudo } \\
\hline $\begin{array}{l}\text { Área total de amostra de } \\
\text { fachada }\end{array}$ & $32264,00 \mathrm{~m}^{2}$ \\
$\begin{array}{l}\text { Área média de amostra de } \\
\text { fachada }\end{array}$ & $336,00 \mathrm{~m}^{2}$ \\
$\begin{array}{l}\text { Quantidade de andares dos } \\
\text { edifícios }\end{array}$ & 6 andares \\
$\begin{array}{l}\text { Material de acabamento das } \\
\text { fachadas } \\
\text { Tipo de substrato do sistema } \\
\text { de vedação }\end{array}$ & $\begin{array}{c}\text { Pastilhas ou elementos } \\
\text { cerâmicos }\end{array}$ \\
$\begin{array}{l}\text { Tipo de estrutura do edifício } \\
\text { Idade das fachadas }\end{array}$ & Concreto armado \\
& 5 a 48 anos \\
\hline
\end{tabular}

A coluna 7 da Tabela II (FD das patologias geral) representa o FD médio obtido a partir da amostra total analisada para cada orientação (Norte, Leste, Sul e Oeste) e ainda do total geral das amostras (Média geral do $\mathrm{FD}=0,26$ ). Ressalta-se que, nesta coluna, as orientações Norte $(0,33)$ e Leste $(0,19)$ apresentam o maior e o menor valor da média de FD considerado para a amostra total, respectivamente. $\mathrm{O}$ fator de dano médio das manifestações patológicas (Tabela II, colunas 2 a 6) mostra que o valor mais elevado ocorre para o total de FD de descolamento de cerâmica na orientação Norte $(0,26)$. Isso pode ser interpretado que para este caso, em média têm-se $26 \%$ da área de fachada degradada por descolamento. O menor valor foi observado para o FD de eflorescência $(0,00)$ nas orientações Norte e Sul.

A Fig. 6 mostra o FD médio das manifestações patológicas que ocorrem nas orientações Norte, Leste, Sul e Oeste. Os resultados do FD são analisados em função dos seguintes termos: média geral (patologia geral); média geral (parcial relativo aos diferentes tipos de manifestações patológicas: descolamento de cerâmicas, falha de rejunte, fissuras, eflorescência e falha de vedação); FD médio nas orientações

Tabela II - Fator de dano médio das manifestações patológicas em função da orientação solar das fachadas. [Table II - Average damage factor of pathological manifestations due to the solar orientation of the facades.]

Fator de dano (FD) médio das manifestações patológicas

\begin{tabular}{ccccccc}
$\begin{array}{c}\text { Orientação } \\
\text { cardeal das } \\
\text { fachadas }\end{array}$ & $\begin{array}{c}(2) \\
\text { Desc. de } \\
\text { cerâmica }\end{array}$ & $\begin{array}{c}\text { Falha de } \\
\text { rejunte }\end{array}$ & $\begin{array}{c}(4) \\
\text { Fissuras }\end{array}$ & $\begin{array}{c}(5) \\
\text { Eflorescência }\end{array}$ & $\begin{array}{c}(6) \\
\text { Falha de } \\
\text { vedação }\end{array}$ & $\begin{array}{c}\text { Patologias } \\
\text { geral }\end{array}$ \\
\hline Norte (N) & 0,26 & 0,05 & 0,06 & 0,00 & 0,03 & 0,33 \\
Leste (L) & 0,18 & 0,02 & 0,05 & 0,01 & 0,02 & 0,19 \\
Sul (S) & 0,20 & 0,05 & 0,04 & 0,00 & 0,02 & 0,25 \\
Oeste (O) & 0,29 & 0,03 & 0,07 & 0,01 & 0,01 & 0,28 \\
Média Geral & 0,23 & 0,04 & 0,06 & 0,01 & 0,02 & 0,26 \\
\hline
\end{tabular}




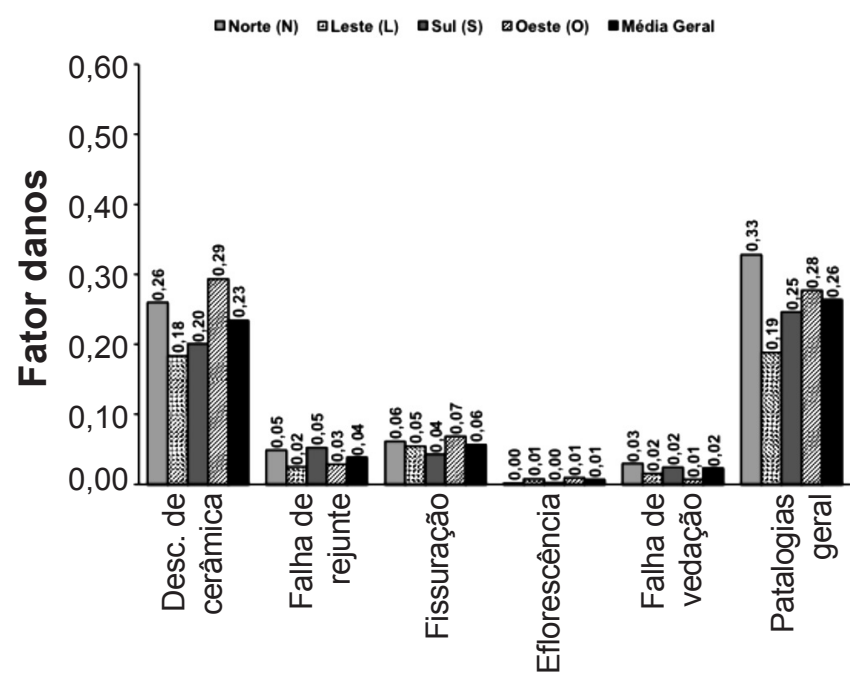

Tipos de patologias

Figura 6: Fatores de danos (FD) médio observado em função da orientação solar das fachadas.

[Figure 6: Average damage factors (DF) observed as a function of the solar orientations of the facades.]

solares (patologias geral); e FD médio de todas as patologias, também nas orientações solares. Em termos de média geral, considerando todos os tipos de danos em relação à amostra total, o maior valor de FD foi de 0,26. Esse valor de FD é bastante representativo uma vez que reflete a extensão média dos danos de todas as fachadas consideradas na amostragem.

Considerando a média geral do FD para os diferentes tipos de patologias (descolamento de cerâmicas, falha de rejunte, fissuras, eflorescência e falha de vedação) se observa que o descolamento cerâmico é a anomalia que mais se destaca, com FD de 0,23. Evidencia-se a importância da magnitude do FD de descolamento quando a mesma é comparada com a segunda anomalia em ordem de intensidade de FD, a fissuração ( $\mathrm{FD}=0,06)$, a qual é muito menor, embora não seja desprezível. A análise em termos das orientações solares para a média total de FD evidencia que as fachadas Norte $(\mathrm{FD}=0,33)$ e Oeste $(\mathrm{FD}=0,28)$ apresentam os maiores processos de degradação. Esses resultados sofrem influência do elevado valor do FD de descolamento para essas mesmas orientações Norte $(F D=0,25)$ e Oeste $(F D=0,20)$. O elevado valor de FD de descolamento de cerâmicas ressalta a influência das tensões térmicas (causadas pela radiação solar) que podem provocar movimentação diferencial entre as camadas do sistema de revestimento ocasionando deficiências de aderência entre os elementos cerâmicos e as camadas subjacentes e, consequentemente, provocando descolamentos cerâmicos nas fachadas. Essa constatação é corroborada ainda pelo reduzido valor de $\mathrm{FD}$ de eflorescência $(\mathrm{FD}=0,00)$, dano este que, de forma diferenciada do descolamento cerâmico, têm a incidência de chuva dirigida e não a radiação solar como um dos principais fatores responsáveis por seu surgimento. Os demais resultados mostram que o maior e menor valor de FD de fissuração foi observado nas orientações Oeste (FD = $0,07)$ e Sul $(\mathrm{FD}=0,04)$, respectivamente. No caso do FD de falha de rejunte, o maior valor foi observado na orientação Norte $(F D=0,05)$ e o menor na orientação Leste $(F D=0,02)$. $\mathrm{O}$ FD de falha de vedação foi mais elevado na orientação Norte $(\mathrm{FD}=0,03)$ e menos elevado na orientação Oeste (FD $=0,01)$. Esses resultados mostram que essas manifestações patológicas oferecem uma pequena cota de participação na degradação das fachadas, uma vez que são sobrepujados pelo elevado valor de FD de descolamento cerâmico.

Neste contexto a Fig. 6 identifica as orientações norte e oeste como aquelas que estão mais susceptíveis à intensidade de ocorrência de danos e evidencia a forte influência da orientação solar na frequência de ocorrência das manifestações patológicas pela exposição à radiação solar das amostras, uma vez que neste caso o fenômeno de degradação depende do nível de exposição das fachadas à radiação solar durante sua vida.

Influência da idade no fator de danos das fachadas (duas faixas de idades: $\leq 10$ anos $e>10$ anos)

A Tabela III apresenta os fatores de danos médio obtido para cada tipo de manifestação patológica agrupada em função da idade das fachadas. Os resultados apontam o descolamento cerâmico $(\mathrm{FD}=0,43)$ como a manifestação patológica mais influente nos processos de degradação em edifícios com idades superiores a 10 anos. Para o grupo com idades inferiores a 10 anos o descolamento também apresentou o maior FD $(0,09)$. Em todas as anomalias estudadas os valores de FD foram sempre superiores para o grupo com idades acima de 10 anos. Os menores valores foram observados para FD de eflorescência $(F D=0,01$ e $F D=0,00)$ e para o FD de

Tabela III - Fator de danos (FD) médio das manifestações patológicas em função da idade das fachadas. [Table III - Average damage factor (DF) of pathological manifestations due to the age of the facades.]

\begin{tabular}{|c|c|c|c|c|c|c|}
\hline \multirow[b]{2}{*}{$\begin{array}{c}\text { (1) } \\
\text { Idade das } \\
\text { fachadas }\end{array}$} & \multicolumn{6}{|c|}{ Fator de danos (FD) médio das manifestações patológicas } \\
\hline & $\begin{array}{c}(2) \\
\text { Desc. de } \\
\text { cerâmica }\end{array}$ & $\begin{array}{l}\text { (3) } \\
\text { Falha de } \\
\text { rejunte }\end{array}$ & $\begin{array}{c}\text { (4) } \\
\text { Fissuras }\end{array}$ & $\begin{array}{c}\text { (5) } \\
\text { Eflorescência }\end{array}$ & $\begin{array}{c}(6) \\
\text { Falha de } \\
\text { vedação }\end{array}$ & $\begin{array}{c}(7) \\
\text { Patologias } \\
\text { geral } \\
\end{array}$ \\
\hline$\leq 10$ anos & 0,09 & 0,02 & 0,07 & 0,01 & 0,02 & 0,13 \\
\hline$>10$ anos & 0,43 & 0,07 & 0,04 & 0,00 & 0,02 & 0,52 \\
\hline Média Geral & 0,23 & 0,04 & 0,06 & 0,01 & 0,02 & 0,26 \\
\hline
\end{tabular}




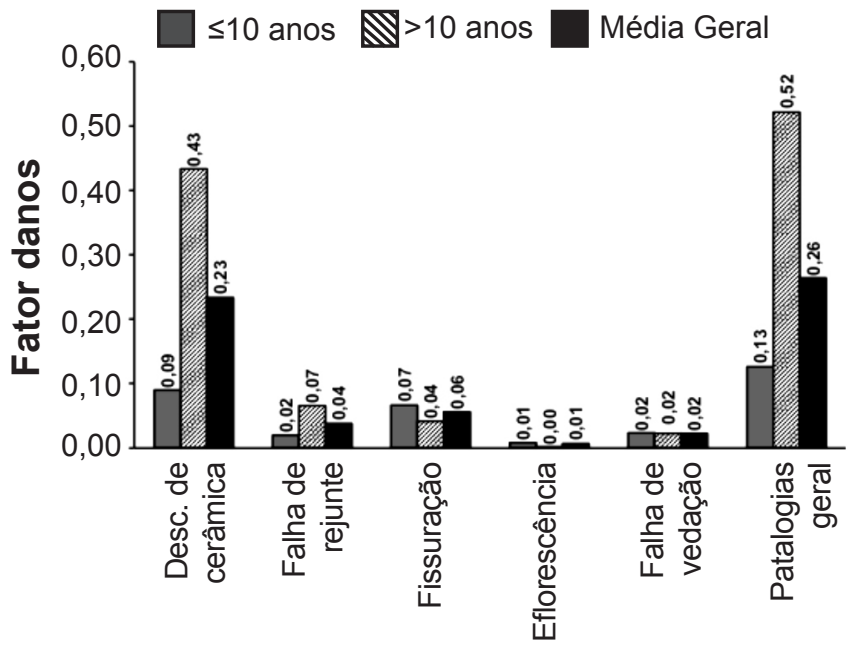

Tipos de patologias

Figura 7: Média do fator de dano (FD) nas fachadas com idades até 10 anos e acima de 10 anos.

[Figure 7: Average damage factor $(D F)$ in the facades aged up to 10 years and above 10 years.]

falha de vedação $(0,02)$. A coluna 7 (FD das patologias gerais) da Tabela III mostra os resultados dos fatores de danos médio em relação ao total de cada grupo de idade da amostra $(\leq 10$ anos e $>10$ anos).

A Fig. 7 apresenta o FD médio das manifestações patológicas que ocorrem nas fachadas com idades até 10 anos e acima de 10 anos. Os resultados do FD são analisados em função dos seguintes termos: média geral e parcial relativo aos tipos de patologias (descolamento de cerâmicas, falha de rejunte, fissuras, eflorescência e falha de vedação) e; média total de FD para as fachadas até 10 anos e acima de 10 anos e média do FD das diferentes patologias também para as duas faixas de idade das fachadas. Os resultados da média geral para os diferentes tipos de manifestações patológicas (descolamento de cerâmicas, falha de rejunte, fissuras, eflorescência e falha de vedação) mostram elevado valor do $\mathrm{FD}$ de descolamento cerâmico $(0,23)$. O FD médio correspondente a amostragem total evidencia que as fachadas com idade acima de 10 anos $(\mathrm{FD}=0,52)$ apresentam os maiores níveis de degradação, o que obviamente era esperado. $\mathrm{O}$ valor mais elevado do FD médio das manifestações patológicas em função da idade foi observado para o FD de descolamento cerâmico $(\mathrm{FD}=0,43)$ em fachadas com idade acima de 10 anos. Os resultados apresentados em função da idade mostram ainda que o FD de descolamento cerâmico, para os edifícios com menos de 10 anos possui uma média de 0,09 e cresce para 0,43 para os edifícios acima de 10 anos. Esse comportamento, apesar de ser em menor proporção, também é observado para o FD de falhas de rejunte, que cresce de 0,02 (até 10 anos) para 0,07 (acima de 10 anos).

O comportamento da fissuração é inverso ao observado para o descolamento de cerâmica e falha de rejunte. Nas primeiras idades (até 10 anos) a fissuração apresenta fator de dano igual a $0,07 \mathrm{e}$, em idades acima de 10 anos, o valor de FD decresce para 0,04 , indicando que, provavelmente, uma parcela deste dano se propagou e acarretou outros tipos de danos. Muito possivelmente uma fissuração detectada nas idades menores possa ter sido convertida em descolamento nas idades mais avançadas. Neste contexto, a distribuição de deformações e ainda a penetração de água através das fissuras podem causar falhas de aderência e explicar o elevado índice de descolamento de cerâmica e ainda do acréscimo do valor de FD de falha de rejunte e falha de vedação observado nas fachadas com idades acima de 10 anos quando comparadas com as fachadas com idades até 10 anos. Os resultados do FD menores para fachadas com idades até 10 anos mostram a importância da detecção e reparação do dano quando de sua origem, evitando dessa maneira a sua dissipação e progressão contínua com o tempo e ainda uma possível sobreposição sobre outros danos.

Comparando os resultados da Fig. 7 com a Fig. 6 observase que para a mesma média geral do fator de dano total (FD $=$ 0,26 ), os resultados parciais do fator de dano total (fachadas $\leq 10$ anos: $\mathrm{FD}=0,13$ e fachadas $>10$ anos: $\mathrm{FD}=0,52$ ) são muito distantes para as duas faixas de idade (Fig. 7) quando comparado com o FD total nas diferentes orientações cardeais (Fig. 6), que apresenta uma distribuição do fator de dano total mais regular. Neste sentido, esse resultado $(\mathrm{FD}=0,26)$ se torna pouco representativo na análise comparativa do FD em fachadas com idades até 10 anos e acima de 10 anos (Fig. 7), contudo, enseja a importância do valor quantitativo do FD na interpretação da influência da idade no processo de degradação das fachadas.

Influência das regiões das fachadas na média de distribuição de manifestações patológicas

A Tabela IV mostra a porcentagem média do total de distribuição de manifestações patológicas para sete regiões de análise dos danos (paredes contínuas, aberturas, sacadas, cantos e extremidades, juntas, transição entre pavimentos e topo) em função do total de danos observados nas amostras. Essa tabela mostra que, em média geral, as falhas ocorrem com maior frequência nas regiões das paredes contínuas (29\%), aberturas (19\%), cantos e extremidades (17\%) e ainda na região da transição entre pavimentos (15\%). A menor intensidade foi observada na região das juntas e topo. Essas regiões sofrem elevadas movimentações diferenciais provocadas por tensões de natureza térmica e mecânica. Esses resultados mostram a influência do confinamento, da continuidade ou descontinuidade do sistema como fatores determinantes no surgimento de manifestações patológicas em fachadas. O estado de confinamento é observado quando o sistema de revestimento está situado entre pilares, vigas e cantos reentrantes. A continuidade do sistema é representada pela elevada extensão da área da fachada. A descontinuidade do sistema é determinada pela existência de aberturas, juntas estruturais, juntas de movimentação e extremidade da fachada. As paredes contínuas apresentaram elevadas intensidades de ocorrência de danos (29\%) em virtude da grande extensão (possuem maior área na fachada) e do confinamento dessa região, sem locais para dissipação ou 
acomodação das deformações que, ao solicitar essa região de forma cíclica e acima de sua capacidade resistente, podem provocar o surgimento das manifestações patológicas. O elevado percentual de danos observados na região das sacadas (12\%) evidencia que estas também são regiões críticas, principalmente por sua configuração, em balanço que provoca, em geral, elevadas tensões, deformações e movimentação diferencial, podendo culminar no surgimento de diversos tipos de manifestações patológicas. As regiões das aberturas, por sua condição, apresentam descontinuidade do sistema de revestimento, portanto, essas regiões são mais frágeis e críticas em função da dissipação das deformações. Essa condição explica o percentual de 19\% de danos observados nessa região. A transição entre pavimentos (15\%) também é uma região bastante crítica. Nessa região ocorre o contato da alvenaria de vedação com a viga do sistema estrutural gerando movimentações diferenciadas elevadas. As manifestações patológicas podem ser atribuídas à ausência de juntas de dilação horizontal que permitam a dissipação das deformações provocadas pela movimentação diferenciada do sistema. Os cantos e extremidades (17\% em idades acima de 10 anos) surgem também como regiões críticas devido ao confinamento (cantos de fachadas) e descontinuidade do sistema (extremidades de fachadas). As demais regiões, apesar de apresentar menores frequências de ocorrência de danos, também são regiões que merecem atenção quanto à intensidade de ocorrência das manifestações patológicas tendo em vista, principalmente, o efeito progressivo dos processos de degradação.

De maneira geral, os resultados mostram a fragilidade dessas regiões em função do confinamento, continuidade e descontinuidade das fachadas evidenciando, principalmente, a elevada fragilidade da região das paredes contínuas para o surgimento de manifestações patológicas.

Tabela IV - Distribuição da frequência de ocorrência de manifestações patológicas nas regiões de análise.

[Table IV - Frequency distribution of pathological manifestations in the regions of analysis.]

\begin{tabular}{cc}
\hline Região das fachadas & Média geral (\%) \\
\hline Paredes contínuas & $29 \%$ \\
Aberturas & $19 \%$ \\
Sacadas & $12 \%$ \\
Cantos e extremidades & $17 \%$ \\
Juntas & $3 \%$ \\
Transição entre pavimentos & $15 \%$ \\
Topo & $6 \%$ \\
\hline
\end{tabular}

\section{CONCLUSÕES}

O descolamento de cerâmica é a principal manifestação patológica responsável pelo processo prematuro de degradação e envelhimento das fachadas. A região de paredes contínuas apresentou elevado índice de intensidade de descolamento de cerâmicas evidenciando que, na maioria das amostras, essa região não consegue absorver e redistribuir de maneira uniforme as tensões térmicas e mecânicas. $\mathrm{O}$ fator de dano (FD) foi eficiente na avaliação preliminar da degradação das fachadas em função da idade e da orientação cardeal nas fachadas dos edifícios. A análise do fator de danos permitiu identificar que as fachadas mais críticas são aquelas com idades superiores a dez anos. Para as fachadas jovens (até 10 anos), esta mesma análise mostrou envelhecimento precoce que pode se tornar crítico caso não se efetuem atividades de manutenção. Os resultados diferenciados nas orientações solares decorrem do tempo e grau de exposição aos fatores e agentes de degradação. $O$ fator de dano atingiu patamares mais elevados nas orientações Norte e Oeste de Brasília. Assim é possível estudar a influência dos agentes de degradação identificando a intensidade dos mesmos nos processos e mecanismos atuantes no surgimento e intensificação das patologias das fachadas. Esse procedimento de análise serve como balizamento inicial do estágio de degradação das fachadas com revestimento cerâmico com o objetivo de mensuração da degradação. Uma vez que se consiga medir a degradação, como o presente estudo se propõe, é possível identificar e correlacionar os principais parâmetros e fatores intervenientes nos processos que degradam as fachadas.

\section{AGRADECIMENTOS}

Ao CNPq e CAPES pelo apoio na forma de concessão de bolsas de pesquisa e ainda ao Laboratório de Ensaio de Materiais - LEM/CDT/UnB, pela disponibilização do acervo técnico e apoio às atividades de pesquisa.

\section{REFERÊNCIAS}

[1] I. Flores-Colen, "Metodologia de avaliação do desempenho em serviço de fachadas rebocadas na óptica da manutenção predictiva", Tese Dr., IST-UTL, Lisboa, Portugal (2009).

[2] ABNT NBR 15575-1, Associação Brasileira de Normas Técnicas - "Edificações habitacionais - Desempenho: Requisitos gerais" (2013).

[3] T. Nireki, Constr. Build. Mat, 10, 5 (1996) 403-406.

[4] LEM, Laboratório de Ensaios de Materiais, Rel. Técnico 06090072-c: "Avaliação da fachada e diagnóstico das patologias identificadas", UnB, Brasília, DF (2006) p.42.

[5] A. F. F. S. Silva, "Previsão da vida útil de revestimentos de pedra natural de paredes", Diss. Mestrado, IST-UTL, Lisboa, Portugal (2009).

[6] I. M. Shohet, Y. Rosenfeld, M. Puterman, E. Gilboa, 8 DBMC, Eds.: M. A. Lacasse, D. J. Vanier, Inst. Res. Constr., Ottawa, Canada (1999) 1670.

[7] P. Hovde, CIB W080/RILEM 175 SLM, Trondheim, Noruega (2004) 1-51.

[8] A. Silva, J. L Dias, P. L Gaspar, J. de Brito, Autom. Constr. 30 (2013) 151-160.

[9] J. D. Silvestre, J. de Brito, Constr. B. Mat. 25 (2011) 
1560-1571.

[10] R. A. Andrade, R. R. Medeiros, L. F. A. Campos, H. S. Ferreira, R. R. Menezes, G. A. Neves, H. C. Ferreira, Cerâmica 57 (2011) 329-337.

[11] R. J. F. Bauer, F. Rago, Ceram. Ind. 5,3 (2000) 41-45.

[12] M. N. B. Silva, A. G. Saraiva, E. Bauer, L. M. Bezerra, E. Bauer, Anais XXIX Jorn. Sud. Ing. Estr., Punta del Este, Uruguai (2000) 3.

[13] E. Bauer, E. Kraus, G. R. Antunes, Anais $3^{\circ}$ Cong. Port. Argamassas de Construção, APFAC, Lisboa, Portugal (2010) 3.

[14] A. G. Saraiva, E. Bauer, L. M. Bezerra, Anais III SBTA, Vitória, ES (1999) 554.

[15] E. Bauer, L. M. Bezerra, J. C. B. Uchôa, S. V. M. das Chagas, "Estudo do comportamento à fadiga das argamassas e sua relação com as patologias e danos nas fachadas", PATORREB (2012) 2.

[16] P. Gaspar, J. Brito, Build. Environ. 43, 11 (2008) 18181828.

[17] P. L. Gaspar, J. Brito, J. Mater. C. Eng. 23, 10 (2011) 1398-1404.

[18] R. Bordalo, J. de Brito, P. L. Gaspar, A. Silva, Build. Res. Inf. 39, 1 (2011) 66-78
[19] E. Bauer, E. Kraus, M. N. B. Silva, Proc. $4^{\circ}$ PATORREB, Santiago de Compostela, Espanha (2012) 2.

[20] M. N. B. Silva, E. Bauer, E. K. Castro, V.A. G. Zanoni, I Simp. Argamassas Sol. Term. Revest.-Argamassa, Coimbra, Portugal (2014) 2.

[21] M. Y. L. Chew, N. Silva, J. Constr. Eng. Manag. 130 (2004) 525-533.

[22] ASTM E632-82, American Society for Testing and Materials - "Standard practice for developing accelerated test to aid prediction of the service life of building components and materials" (1996).

[23] D. C. W. Ho, S. M. Lo, C. Y. Yiu, L. M. Yau, Hong Kong Surveyor 15, 2 (2004) 7-11.

[24] J. Niu, Energy Buildings 36 (2004) 1259-1263.

[25] P. Gaspar, J. Brito, J. Const. B. Mat. 19, 8 (2005) 571578 .

[26] G. R. Antunes, "Estudo de manifestações patológicas em revestimento de fachada em Brasília - sistematização da incidência de casos", Diss. Mestrado, UnB, Brasília (2010). [27] E. Bauer, E. Kraus, G. R. Antunes, Anais IX SBTA, Belo Horizonte, MG (2011) 4.

[28] E. Bauer, E. K. Castro, G. R. Antunes, F. E. Leal, Proc. XII DBMC, Porto, Portugal (2011) 2. (Rec. 18/09/2014, Ac. 18/03/2015). 